Fecha de recepción: diciembre 2018 Fecha de aceptación: marzo 2019 Versión final: abril 2019

\section{El diseño como objeto artesanal de consumo e identidad}

Mónica Susana De La Barrera Medina *

Resumen: Desde sus inicios el trabajo de diseño gráfico tuvo la intención de reproducirse y multiplicarse, siendo el trabajo editorial y sus diversas publicaciones las que, bajo los principios de difusión generaron ediciones cada vez más altas, tanto en número como en calidad. Sin embargo y en un contexto de posmodernidad, donde los contenidos simbólicos y materiales, por mencionar algunos han ido cambiando, se sostiene que en la actualidad y quizás en un volver al origen, se presenta la tendencia de realizar productos de diseño únicos, por ende artesanales que además algunos se muestran sustentables, con uso y reutilización de diversos materiales. Lo antedicho implica el uso de menos basura, cierta innovación y evidentemente hacen de estos objetos piezas únicas e irremplazables. De allí que el texto analice desde diversas visiones, sustentadas en la metodología de las entrevistas, acerca del trabajo de diseñadoras que apuestan al trabajo artesanal como una intervención para proyectos como carteles, libros y otros objetos de diseño. La propuesta conjuga un acercamiento al diseño contemporáneo, en un intento de asimilar su valoración frente a un mundo casi inmaterial.

Palabras clave: artesanal - diseño contemporáneo - identidad - producción - valoración

[Resúmenes en inglés y portugués en las páginas 105 - 106]

${ }^{(*)}$ Doctora en Antropología Social por la Universidad Iberoamericana (Ibero, Ciudad de México), Maestra en Diseño por la Universidad Autónoma de San Luis Potosí (UASLP, San Luis Potosí, México) y Licenciada en Diseño de la Comunicación Gráfica por la Universidad Autónoma Metropolitana (UAM-Azcapotzalco. Ciudad de México). Desde hace más de 19 años profesora en diversas universidades de México y desde el 2002 Profesora de Tiempo Completo en la Universidad Autónoma de Aguascalientes (UAA, Aguascalientes, México) en el Centro de Ciencias del Diseño y de la Construcción, investigadora Perfil Deseable PRODEP, catedrática en materias de Identidad Corporativa, Tipografía, Taller Integral y Presentación de Proyectos Profesionales, entre otras. Sus trabajos de investigación abordan temas de: diseño y comunicación gráfica, antropología del diseño, innovación, urbanismo y diseño. Correo: msdelaba@correo.uaa.mx 


\section{Lo artesanal en el desarrollo del diseño}

El sociólogo Richard Senett (2009), precisa que el oficio es una experiencia exploratoria que como está focalizada en la realización correcta de una técnica, obtiene como recompensa el respeto personal. En efecto, las destrezas y habilidades se obtienen con el paso del tiempo, solo con paciencia y perseverancia, realizando día con día trabajos que se van mejorando la técnica. El posicionarse como un artesano respetable puede requerir años de trabajo, ese tipo de reconocimiento que aquellos que lo han alcanzado lo pueden aquilatar, pues se trata de una recompensa emocional. En su libro El Artesano, Senett (2009) se centra en el punto de vista del hacedor de taller, aquel que realiza el trabajo manual y que incluso llega a obsesionarse con los detalles, pues el artesano representa la condición específicamente humana del compromiso, en el que van unidas la mano y la cabeza.

Este dilema es fundamental para repensar desde la actualidad el papel del diseñador como artesano, si su trabajo requiere del detalle o de la producción multiplicada, independientemente de su fusión de la mano con la cabeza para crear, en una era que pasó de lo industrial a la de la información (Castells, 1997). De este modo el desempeño del diseñador está inmerso entre la globalidad y la identidad, en medio de la revolución tecnológica que supone cambios radicales en el desarrollo creativo.

$\mathrm{El}$ artesano o gente de oficio fue siempre un especialista que a lo largo del tiempo incrementó saberes aprendidos y practicados. Es a partir del aprender haciendo, con errores y aciertos que fomentó habilidades y realizó diversas obras. Asimismo, este conocimiento adquirido fue transmitido de una a otra generación, de forma directa, de persona a persona entre un maestro y aprendiz. Dicho conocimientos la mayoría de las veces es transmitido de manera práctica y tácitos a través del ejercicio de la técnica y constituyen el hacer del oficio. Sennett (2009) describió por un lado, la capacidad/habilidad que un individuo tenía en tanto recursos, talento y la aptitud para el desarrollo de determinadas prácticas para las cuales estaba adiestrado como opuestos a la inspiración súbita (capacidad de hacer algo de manea innata). Por otro lado, el dominio, el conocer y saber como características del artesano también pero en calidad de demostración a los demás de que algo está bien hecho.

La capacidad de realizar en determinado momento trabajos con habilidad, porque se es capaz de aprender y hacerlo es universal. No obstante dicha destreza se desarrolla conforme se practica y ejercita dicha destreza. El oficio es un conocimiento tácito, personal y paradójicamente también está anclado en los saberes del grupo. Dichos conocimientos no son fáciles de plantear a través del lenguaje formal, ya que se transmite a través de la experiencia del aprender haciendo y del aprender interactuando, que involucra la interacción cara a cara de forma directa, conocimientos que difícilmente pueden ser removidos de su contexto humano y social y que están ampliamente referenciados en las prácticas corporales (Nonaka, 2007, Lundvall y Johnson, 2016).

En el caso de la producción de libros, para el desarrollo de las primeras publicaciones, los oficios jugaron un papel fundamental. En efecto, se requería de diversos expertos artesanos para la realización de un libro. El trabajo en talleres se apoyó en herramientas que requerían de amplia maestría y dominio, incluso estas herramientas se fueron modificando para lograr mejores resultados, y el producto libro se fue transformando de elementos 
rudimentarios a sofisticados. De este modo también se fue acrecentando y favoreciendo la creatividad, desde su concepción, hasta la entrega del producto terminado. Ejemplares editoriales con detalles en piel, grabados, con tintas especiales y pigmentos derivados de la alquimia realizados para diversos y exigentes clientes, que encontraron en los expertos de oficio resultados de mucha calidad, obras de arte únicas.

Sin embargo, el desarrollo tecnológico fue sustituyendo, mecanizando y sistematizando buena parte de estas labores. Las máquinas fueron asumiendo actividades, reduciendo tiempo en los procesos e incrementando la producción. No obstante, con la sistematización también desapareció la posibilidad de pensar durante el proceso de realización y de realizar modificaciones durante el mismo. Asimismo, también se interrumpió el legar los conocimientos tácitos de gente de oficio, que por muchos años dominó el trabajo artesanal (Coriat, 1992), a otros de forma directa de modo tal que obtuvieran algún tipo de aprendizaje no documentado.

En la actualidad la industria editorial maneja grandes cantidades de producción de libros mecanizada. Esto implica que los libros se diseñan en un determinado lugar, pero son las grandes imprentas las que los reproducen y también los comercializan en espacios que ya no son físicos, pues los ejemplares permanecen en almacenes guardados y ya no exhibidos en librerías y su venta es a través del internet. No obstante la venta de libros físicos cada vez es menor, pues la tendencia ha generado las versiones intangibles en los libros digitales. Estos productos sin lomo, sin solapas y que pueden conservarse en archivos o programas virtuales, ocupando un espacio sólo virtual en la memoria de algún dispositivo electrónico, descargables y visibles en diversos formatos. Algunas de sus diferencias es que no se pueden oler o tocar, no tienen peso específico, solo se sabe que se tienen. Los libros como objetos o productos derivados de un trabajo creativo, son un ejemplo de lo que se puede tener sin sentir el estímulo de las emociones, fundamental para el bienestar humano (Damasio, 2002).

Hasta aquí se dio cuenta de cómo lo artesanal fue parte del surgimiento y acompañó el proceso de diseño como parte del hacer. A continuación se verá cómo incidió este proceso en el conocimiento de diseño.

\section{Conocimiento para el trabajo de diseño}

En la labor artesanal, el conocimiento se obtiene de manera corporal, con técnicas y prácticas del cuerpo, por ejemplo, en la mano a través del tacto y el movimiento. Es a través de la imaginación que comienza la exploración del lenguaje, que se intenta dirigir y orientar la habilidad corporal (Sennett, 2009). Este lenguaje alcanza su máxima funcionalidad cuando muestra de modo imaginativo cómo hacer algo, incluso mediante la utilización de herramientas imperfectas o incompletas, estimulando la imaginación para desarrollar habilidades aptas para la reparación y la improvisación (2009:53). Asimismo, un diseñador también idealmente debe poseer habilidades en el empleo de sus herramientas, en su formación y dentro de su trabajo profesional. Además, debe ser evidenciar el dominio de ello desde su conocimiento simbólico para ofrecer soluciones adecuadas. 
Asheim (2007) distingue dos tipos de conocimiento: el sintético y simbólico. El primero basado en la ingeniería, aquel en el que se aplica la experiencia, la capacidad de combinar lo que se sabe con la experimentación, las pruebas y en el trabajo práctico en el aprender haciendo, para dar soluciones y resultados. Por ejemplo aquí se puede ubicar a un especialista de taller, que domina la maestría de su trabajo. Por otro lado, el conocimiento simbólico está basado en la creatividad, que Asheim identifica cómo aquel que sabe-cómo, derivado de las destrezas y habilidades prácticas especializadas en la interpretación de símbolos culturales, más que del procesamiento de la información. Este conocimiento es específico del contexto en el que se desarrolla, pues la interpretación de símbolos, imágenes, dibujos, historias y artefactos culturales, están fuertemente ligados a una comprensión más profunda de las costumbres, las normas y la cultura cotidiana de grupos sociales específicos. De allí que este tipo de conocimiento sea el que predomina en el diseño, como una disciplina integradora, ya que de acuerdo a Augé (2000), el diseño es nexo activo en las comunicaciones humanas que pone como protagonistas a los objetos industrializados, ya que "sirven para medir, probar y modificar el estado de la relación entre los interlocutores del juego social" (Augé, 2000).

A propósito de los 100 años de la Bauhaus, es importante recordar a esta escuela de arquitectura, artesanía y diseño, cuyo enfoque justamente estuvo orientado hacia el trabajo manual. Más aún, en ella el trabajo artesanal fue prácticamente una ideología y en la que se realizaron proyectos con resultados surgidos de necesidades, que asimilaron y fusionaron el trabajo de oficio con vertientes teóricas de arte. El artista en esta escuela, fue resultado del perfeccionamiento del artesano y la fusión de los conocimientos integradores. Un lugar visionario que planteó el desarrollo de proyectos en los que la maestría fue parte del trabajo de dominio, con diversas disciplinas, cada una con sus habilidades dirigidas a tareas específicas en las muy variadas áreas del diseño combinadas en un modelo de escuela-taller-laboratorio (Droste, 2006).

La Bauhaus fue tan importante, que se replicó en casi todas las escuelas de diseño posteriores a su fundación, retomando sus avances, su objetivo definido por Walter Gropius fue la recuperación de los métodos artesanales en la actividad constructiva, elevando el trabajo artesanal tanto como las Bellas Artes. La meta era comercializar productos integrados a la producción industrial para convertirlos en objetos de consumo posibles de adquirir para más personas, una fusión entre el artista y el artesano o visto de otro modo, entre el arte y la técnica. Bajo esta premisa fueron muchas las instituciones educativas enfocadas a las áreas de diseño que consideraron al trabajo artesanal como parte de los aprendizajes que sus alumnos debían replicar. Incluso varias universidades de México llegaron a contar con licenciaturas en artesanía, como una oportunidad, enfocadas a la recuperación de conocimientos culturales de las diversas áreas que lo artesanal tiene, desde lo textil en bordados, los sistemas de producción como telares de cintura hasta lo objetual con vasijas y piezas en materiales como la cerámica, piedra o madera. Al menos en México y con la cantidad de artesanías y conocimientos sectorizados por regiones y zonas culturales, la creación de una licenciatura parecía necesaria, sobre todo para poder legar el patrimonio, favoreciendo el conocimiento y dominio de técnicas y materiales específicos del quehacer manual. Sin embargo la mayoría de estas escuelas fueron cerrando, llegando a considerar prioritaria cualquier otra licenciaturas en diseño, menos lo artesanal. 
Muchas universidades en México, ofrecen las diversas especialidades en diseño, industrial, gráfico, de modas, de interiores, pero sus asignaturas contemplan mayoritariamente el aprendizaje de técnicas de representación digitales por encima de las manuales. De hecho las personas de oficio que podían legar sus conocimientos a los alumnos, han sido también desplazadas, pues las universidades contratan a aquellos que poseen un título avalado oficialmente, con licenciaturas, maestrías o doctorados que por supuesto los artesanos expertos o gente de oficio no posee, pues ellos se formaron con la experiencia sin una validación oficial o un saber institucionalizado. De ahí que muchas de las carreras universitarias en diseño tengan contenido curricular con mayor interés en el desarrollo tecnológico, al menos eso lo parece con asignaturas que enseñan el manejo de herramientas digitales y muy poco trabajo manual, las materias de taller son reducidas, no se enfocan al trabajo y descubrimiento de materiales para diversos resultados, puesto que los tiempos de estudios de una licenciatura también se han venido reduciendo en años de estudio, restándole la posibilidad a los alumnos de experimentar y desarrollar sus propios aprendizajes mediante la práctica del aprender haciendo.

En contraparte, y de manera complementaria al fenómeno educativo reseñado, comenzaron a surgir desde hace por lo menos cuatro años en México, pequeños talleres o escuelas de menor número de alumnos, que ofrecen cursos impartidos por especialistas de diversas áreas cercanas al diseño, en su mayoría derivadas de las asignaturas tradicionales que ya no se imparten en las universidades. Caligrafía, aerografía, impresiones con tipos móviles, serigrafía o joyería artesanal, son algunos de los talleres enfocados al trabajo manual, cursos cortos en espacios excepcionales en los que concretamente se trabajan técnicas, se experimenta con materiales, y se realizan prácticas que favorecen el conocimiento sintético y simbólico, fundamentales para recuperar el dominio de algunos oficios aplicados al diseño.

\section{Diseño único de ayer y siempre}

No se trata de nostalgia, cuando se analiza un modelo de enseñanza que antecedió la propuesta curricular de enseñanza del diseño institucionalizada en la actualidad. En su momento, como se sostuvo, en México se contaba desde el diseño con una gran parte de trabajo artesanal, como el Taller de Integración Plástica (TIP) que surgió en 1949, posteriormente en 1952 se abrió El Taller de Artesanos Carlos M. Lazo, perteneciente a la Secretaría de Comunicaciones y Obras Públicas (SCOP), con la incorporación de esta área de formación al Instituto Nacional de Bellas Artes (INBA), el INBA estructura por primera vez los estudios con programas y reglamentos mínimos (Kloss, 2006), convirtiéndose posteriormente en 1961 en Escuela de Diseño y Artesanías, y que finalmente en 1980 se consolidó como Escuela de Artesanías y que a la fecha continúa impartiendo carreras de técnico artesanal ${ }^{1}$.

Como podemos apreciar, en realidad el desarrollo de objetos artesanales sigue siendo importante y socialmente necesario. Es más, prevalecen los objetos culturales y simbólicos, que más allá de su base material conllevan una carga significativa, que trascienden porque su uso ha sido fundamental, por ejemplo, para preservar alguna tradición tal como lo reconoce Bordieu (2007) argumentando que el mundo social está condicionado por sis- 
temas simbólicos. Por ejemplo en diversas regiones de América, la realización de textiles con fibras animales o vegetales permite resguardar la memoria histórica, lo mismo que con el uso de pigmentos, que no obedece a la falta de recursos o disposición limitada, sino que conlleva cargas simbólicas al recuperar la manufactura tradicional regional, en la que se depositan los conocimientos ancestrales, por manos que dan sentido al simbolismo de la prenda y de quien los porta. Son diversos los motivos iconográficos en los textiles, en la alfarería y en los demás objetos artesanales, y cada uno responde por lo general a significados emblemáticos de grupos culturales. Puede verse en algunos trabajos como los de Devia, Cardale y Niño Izquierdo (2016), en estudios sobre colorantes empleados en comunidades indígenas, donde su uso depende de normas ancestrales de la comunidad. En el caso de los textiles ha sido tan atractiva la imagen de algunas piezas realizadas a mano, que, en algunos casos, grandes empresas comerciales se han apropiado del diseño original de diversas comunidades. Por ejemplo, reproduciendo en prendas de vestir, estilos reconocidos de culturas mexicanas, caracterizados por los colores llamativos y grandes flores y bordados ${ }^{2}$. Sin embargo, empresas extranjeras con mayor tecnología, han intentado emular el diseño bordado hecho por manos de mujeres artesanas, sustituyéndolo con materiales semejantes a los originales, pero con impresiones o bordados de alta calidad fabricados por máquinas, que a simple vista parecieran auténticas, si no fuera por la cantidad de prendas reproducidas y vendidas en cadenas de almacenes.

Esto, por supuesto, es un problema ético que vale la pena discutir, ya que se trata del uso de identidades insertadas en aplicaciones comerciales, qué al no tener un registro o patente de uso por cada artesano, parecen estar a disposición de quien desee apropiarse de ello. Pero el planteamiento del diseño, del trabajo original que deriva en innovación y nuevas propuestas, también se ha venido recuperando. La ciencia ha estado a colaborando en obtener nuevos materiales, algunos derivados de la naturaleza, que posibilitan mejoras en el medio ambiente y una contribución a favorecer el consumo responsable de productos variados, por ejemplo materiales verdes en la industria de la construcción, materiales reciclados, renovables, no tóxicos, de reuso y diversos lineamientos establecidos por certificaciones internacionales

Algunos diseñadores han intentado recuperar en sus propuestas el trabajo artesanal, incluso cuando su diseño rebasa fronteras y se imprime en grandes cantidades, como en los carteles o en la identidad corporativa. Es por ello que el trabajo único, el artesanal, no desaparece, se recuperan ciertas técnicas o modos de realizar soluciones, pero se puede incorporar a lo actual, pues se han simplificado recursos y tiempos de la mano con el trabajo creativo. De este modo el trabajo de oficio puede ser de mucha más calidad con objetivos específicos y alcances del enfoque del diseño. Al respecto puede verse en la propuesta de Ana Elena Mallet y Pilar Obeso en su proyecto "Hilos y entramados", realizado en el 2016 con el apoyo de la Secretaria de Cultura de México, el proyecto que ha fomentando el rescate de productos artesanales y originales, a través de prácticas colaborativas con distintos diseñadores a modo de diálogo ${ }^{3}$. 


\section{Modelos de producción y la presencia del diseño}

El valor de un producto se modifica por supuesto de uno único a otro común o repetido, porque los objetos se viven de distinta forma, como lo planteo Baudrillard (1969), con valores de uso, de signo y de cambio, porque desempeñan un papel regulador en la vida cotidiana. En un objeto artesanal no solo vemos su funcionalidad, sino el trabajo que detrás está implícito.

En el modelo fordista, donde su producción masiva respondió a fabricaciones lineales de ensamblaje de productos y los trabajadores realizaban tareas repetidas, la evidente industrialización trajo consigo mayor cantidad de objetos fabricados por máquinas, menor costo para un consumidor, como ejemplo Henry Ford logró reducir el tiempo de montaje de un automóvil "desde 12 horas y 28 minutos (septiembre de 1913) a 1 hora y 33 minutos" (30 de abril de 1914) (Horace y Faurote 1915, 323). El modelo fordista implicó la mecanización de cadenas de montaje, acompañada de nuevas normas de consumo masivo, acceso a bienes de consumo durables por parte de los asalariados- y nuevas normas de vida de los trabajadores urbanos (Neffa y De la Garza Toledo, 2010). Sin embargo la centralización de grandes compañías con producción masiva, trajo también una serie de problemas sociales al desplazar buena parte del trabajo humano que poseía conocimientos únicos, en realidad desplazando a la mano de obra especializada y mecanizándola (Coriat, 1992), con un aumento del trabajo improductivo en las empresas, pero con un alto reconocimiento de la marca y su identidad justamente por esa masividad.

Con el paso hacia el posfordismo, las relaciones entre los recursos naturales, los sectores secundarios y terciarios, se modificaron sustancialmente, cada sector se subdividió y se especializó. De dio lugar a bloques de productos perfeccionados y acabados, a través de compañías pequeñas y subsidiarias, que resolvieron problemas de logística, de especialización, de descentralización. Lo antedicho permitió el aumento en el desarrollo de actividades económicas, diversificación de los productos, equipo de trabajo y personal especializado, que incluyó el trabajo de mujeres, pero que también trajo consigo mayores consumos de acuerdo a Neffa y De la Garza Toledo (2010).

En la actualidad los modelos se han modificado, lo mismo que la producción, permitiendo una asimilación distinta de lo objetual. Dando lugar a cuestionarse la posición como diseñadores, por un lado la fragilidad como consumidores que desean una marcada individualidad como lo plantea Bauman (2003), pero, por otro lado, la tendencia a adquirir cosas de menor valor y al mayoreo.

Otras de las diversificaciones, apela a los consumidores activos (Gillmor, 2006), donde la personalización de productos por parte de un cliente lo va convirtiendo en el diseñador de lo que desea adquirir en función de sus intereses y gustos. Pero el encanto de la personalización de los productos está centrado en algunas empresas en la forma, más allá de modificar su contenido. De ahí que lo externo se vaya adecuando a gustos y que, por ejemplo, una empresa consolidada cómo Coca cola, pudiera ponerle el nombre de "Luis", a un producto que siempre será identificado por su contenido.

Otra tendencia de consumo muy reciente, puede identificarse por lo orgánico, lo sano o lo natural que ha dado lugar a diseños sectorizados. Incluso porque en el desarrollo de etiquetas se regresa a considerar a las propuestas más puras en términos de diseño, aquellas 
en las que una sola tinta pueda describir y detallar el contenido, conservando contrastes y jerarquías. La serigrafía se retoma, pero ahora con tintas ecológicas o papeles hechos a mano o reciclados, qué en una propensión a cuidar el medio ambiente, se destinan incluso los envases de vidrio a ser usados y rehusados para comprar y degustar determinados productos. Así de forma muy general se han venido simplificando productos y con ellos las aplicaciones de diseño, etiquetas sin plástico, bolsas de papel y el menor uso de materiales que contaminen. Los anaqueles, exhibidores y aparadores también se van depurando de elementos, hasta dejar en tablas de madera casi sin pulir o de metal un tanto oxidados, productos limitados, de los que hasta la caducidad y vigencia van escritos a mano para dar una idea de lo poco industrial que ahora es. Entre más artesanal sea el mensaje se intenta que parezca más natural. Todo esto corresponde a una tendencia e inversión, tal como lo afirman publicaciones de estudios económicos (Esnaurrizar, 2017), en donde los alimentos orgánicos representan un prestigio incluso para las mismas grandes industrias, limitando en ediciones casi el mismo producto pero presentándolo en distinto contenedor, en la búsqueda de generar también una conciencia para reducir el impacto ambiental, pero enlazándolo siempre al consumo y el consumidor, a través de una construcción de identidades, una tendencia de consumo utilizada por las marcas para crear en los consumidores una identidad con la que se vean reflejados (Marinas, 1998).

\section{El trabajo artesanal de dos diseñadoras}

Lo artesanal, menciona Rotman (2003), es una manifestación que representa y modela identidades, relacionadas con la nacionalidad, que remite a tradiciones y que da sustento a una identidad cultural de una sociedad y lugar determinado. De este modo lo artesana se identifica con valores e ideas de la historia regional y nacional, por lo que forman parte de un patrimonio, con diversas implicaciones simbólicas. Con esta premisa y para dilucidar entre la artesanía y el diseño, se invitó a dos mujeres diseñadoras de distintos países para conocer a través de algunas preguntas, sus puntos de vista centrados en una actualidad altamente tecnológica.

Por un lado, Parisa Tashakori que es una artista visual y diseñadora gráfica con licenciatura y maestría en diseño gráfico, nacida en Teherán, capital de la República Islámica de Irán, que actualmente reside en Estados Unidos. Esta diseñadora es reconocida internacionalmente como profesora y miembro del jurado en importantes competencias y festivales en el mundo del diseño. Por otro lado, Gabriela Irigoyen, de origen argentino, está desde los seis años de edad radicada en Brasil. Es maestra, artista visual y se dedica a hacer libros artesanales desde 2004. Ambas diseñadoras cuentan con una amplia trayectoria, y su trabajo resulta inspirador, al incorporar el trabajo artesanal a sus proyectos actuales de diseño ${ }^{4}$. Cuando se le preguntó a Parisa la diferencia que encuentra entre el diseño y la artesanía, ella replanteó la pregunta: ¿Qué conecta diseño y artesanía?, respondiendo que la raíz del diseño proviene de la artesanía, considerando que nuestros antepasados artesanos abrieron el camino, por lo que fueron justamente los primeros diseñadores (Tashakori, $\mathrm{P}, \mathrm{co}-$ municación personal, noviembre 28, 2018). 
Durante su infancia Parisa, pasó mucho tiempo con familiares en reuniones de mujeres, quienes la mayor parte del tiempo estaban ocupadas haciendo manualidades cosiendo, bordando y tejiendo, "A veces era como un concurso, ellas trataban de crear algo nuevo y hermoso para sus hijos o para decorar su casa" (Tashakori, 2018). Describió con franqueza que no le gustaba este tipo de trabajo, tan ligado al género femenino, pues en esos momentos ella deseaba tener más libertad para a andar en bicicleta o jugar en la calle con otros niños. Sin embrago al crecer y sobre todo al convertirse en diseñadora gráfica, comenzó a usar todo su conocimiento de infancia, "Encontré que a mi público le gustan estos diseños y los admiro más” (Tashakori, 2018).

La riqueza e historia del país del que proviene Tashakori, lo aquilata y lo reconoce, por lo que siempre ha buscado conectarse con sus antecedentes (ver imágenes del 1 al 5). Por ejemplo considerando trabajos cómo el que se realizó en montañas sagradas en Irán, Alvand Mountain con inscripciones en piedra ${ }^{5}$. Este trabajo histórico fue en su momento encargo de un cliente, uno de ellos ordenado por Darío el Grande (521-485 aC) y otro fue diseñado para Jerjes el Grande (485-465 aC), como ejemplos de las obras maestras que permiten ver el trabajo que perdura a través del tiempo, apegado al trabajo artesanal.
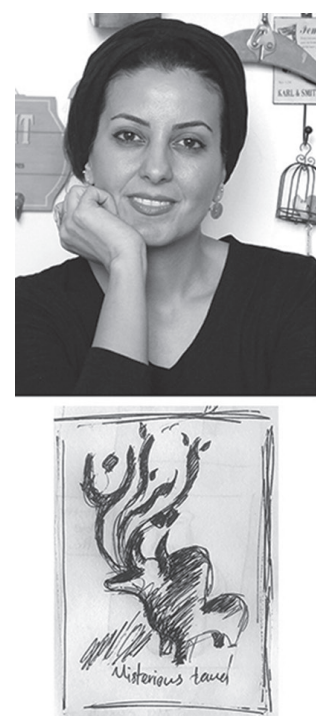
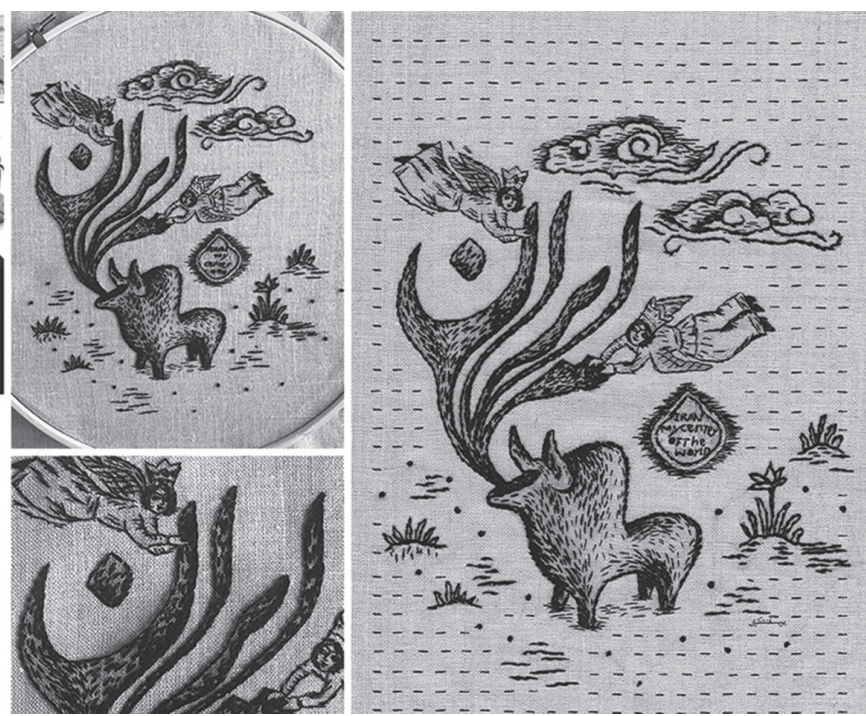

Imagen 1, 2, 3, 4 y 5. Parisa Tashakori, su imagen y ejemplos de su desarrollo para el trabajo en Cow Internatinal Design festival, titulado: My Center Of the World, desde el boceto, el bordado a mano con bastidor, hasta el cartel final impreso y expuesto en la exhibición en 2017, sobre la vaca en la mitología de Irán. Fuente: Imágenes enviadas por la autora y editadas como collage. 
Parisa es una diseñadora situada en la frontera de dos generaciones, pues como ella lo explica, comenzó su carrera como diseñadora usando pinceles, colores, letraset, airbrush, zipatone, fotocopiadoras y muchos otros recursos con los que realmente disfrutó trabajando. Más tarde las computadoras y la revolución de internet le cambiaron todo.

"A veces pienso que vamos a olvidarnos incluso de escribir porque todas nuestras notas, números de teléfono y calendarios están en nuestros teléfonos inteligentes, lo cual es bueno en algunos aspectos, especialmente en términos de ahorro de entorno. Pero todavía estoy conectada al papel. Prefiero leer libros y dibujar en mi cuaderno personal. Además, muy pocos diseñadores gráficos vuelven a hacer arte físico, así que decidí revivir mi estilo de arte original nuevamente, un estilo que a todos les gustaba: todas las artesanías de arte femenino" (Tashakori, 2018).

El trabajo de Parisa justamente lleva ese trabajo manual aplicado en diversos medios, como el cartel. Le pregunté qué diría a los jóvenes estudiantes que creen que la tecnología y el uso de la computadora hacen todo el diseño. Respondió que los alumnos deben confiar en sus ojos, mentes y manos, pues ese triángulo puede transformarlos de un operador informático a un diseñador. Para ella un diseñador es un solucionador de problemas y funciona como una herramienta universal para los clientes. "Si no tienen habilidades en dibujo, fotografía, ilustración, creatividad y muchas otras habilidades que un diseñador gráfico necesita saber, ¿Cómo podemos ayudarles a comercializar sus productos o servicios?" (Tashakori, 2018).
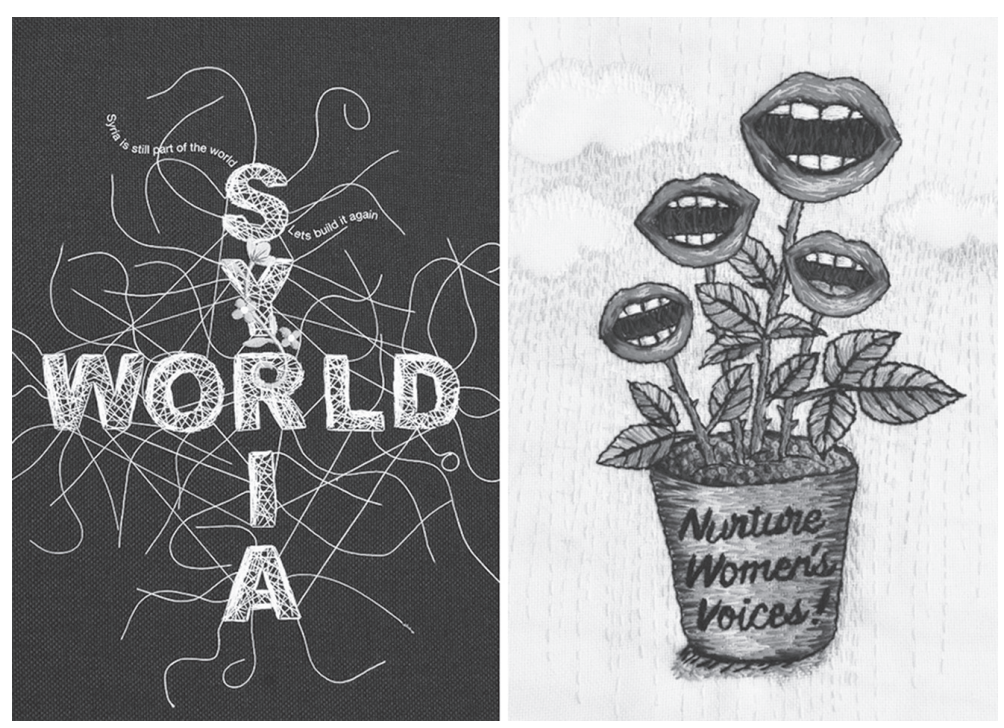

Imagen 6 y 7. Fuente: http://www.parisatashakori.com/ (2017) 
Algunos de los carteles de Parisa tienen evidentemente trabajo artesanal y conllevan intereses sociales, artísticos y ambientales. La imagen 6 es de la colección Poster Without Borders. La imagen 7 es de una exposición de carteles en Polonia, Women's rights are human rights, su cartel ¡Cultiva las voces de las mujeres!, con el que promueve nutrir las voces de las mujeres para animarlas a hablar y defender sus derechos humanos básicos en cada una de sus comunidades.

Parisa considera que es mejor desarrollar un lenguaje personal en lugar de un estilo para un diseñador, ya que un estilo nunca es creado por una persona específica, y en poco tiempo no se puede desarrollar un lenguaje artístico personal, sin pasantías y otras oportunidades de aprendizaje con maestros, con trabajo arduo y lectura. "El lenguaje personal es algo que no puedes inventar intencionalmente; Simplemente aparece por sí mismo después de muchos años de experiencia durante tu trabajo profesional" (Tashakori, 2018).

La diseñadora describió que siempre disfrutó probando diferentes experiencias, que en algún tiempo fue criticada por algunos colegas por no tener un estilo o acento específico en sus trabajos profesionales. Algunos incluso mencionaron que no era lo suficientemente leal a la tipografía persa proviniendo de Irán. Pero esto no le importó en absoluto, porque cree que cuando eres joven o trabajas como un joven diseñador, debes probar todas las técnicas y estilos, y será hasta después de algunos años cuando te encontrarás más cerca y más cómodo con algunos de tus diseños. "Ahora parece que a todos les gusta ver el trabajo que he hecho con mis manos, como bordar y tejer, lo cual es bueno porque también disfruto haciendo ese tipo de trabajo. La clave es recordar que como diseñador es muy importante utilizar estas habilidades para el diseño, no solo para hacer arte aplicado a lo ordinario" (Tashakori, 2018).

Por su parte, para Gabriela Irigoyen la buena artesanía también es un proyecto de diseño, pues es necesario planear, estudiar los materiales, pensar en cómo será su utilización y aprovechamiento, sobre todo en qué medida ese objeto creado será útil o atractivo de alguna manera. Son también las premisas básicas del buen diseño (Irigoyen, 2018).

Para esta diseñadora el uso de los materiales es fundamental, ya que ella busca utilizar y reutilizar todo tipo de papel y recuperarlo en diversos formatos de libros que hace a mano, explorando con diversos tipos de encuadernado y cocido. En sus trabajos resalta ante todo el trabajo artesanal de forma casi pura, evidenciando que no solo el contenido literario del libro es importante, sino el formato libro en tanto objeto que más tarde permitirá llenarse de información.

Irigoyen explicó que todo su trabajo de diseño está relacionado con el trabajo artesanal (ver imágenes del 8 al 11). Es el trabajo manual el que le ha permitido crear y probar nuevas estructuras para crear sus libros e innovar en su parte estética y estructural, con nuevas formas de sujetar y disponer las páginas, nuevos cosidos y formas de mantener las tapas y hojas unidas, de una forma durable y estéticamente agradables. Ella sabe claramente que la gente adquiere sus diseños porque buscan algo único, algo que quieren guardar.

El realizar trabajo artesanal actualmente en un medio tan tecnológico, permite probar los materiales de forma que la pantalla de la computadora no permite hacer. Es posible sentir texturas, pesos, olores, o el cómo reaccionan materiales distintos uno cerca del otro, el trabajo manual permite la sinestesia (Irigoyen, 2018). A jóvenes alumnos que creen que la tecnología y el uso de computadora hace todo el diseño les diría que es muy importante 
que se permitan sentir, oler, tocar, percibir los materiales y escuchar lo que les dicen sobre cómo utilizarlos para hacer un diseño mejor, más agradable y qué no haga daño al planeta (Irigoyen, 2018).

En su experiencia ella considera que por lo menos son cinco años los que puede tomarle a un diseñador saber su estilo de trabajo, describe Irigoyen que para ella su trabajo es particular porque es posible hacer libros que encanten a las personas y les den ganas de tenerlos. Ella se ha dedicado de forma constante a investigar y estudiar la historia del libro y las técnicas tradicionales de encuadernación, para interpretar de forma contemporánea y artística el arte de hacer libros.

Irigoyen ha incorporado el trabajo de su esposo y calígrafo Claudio Gil en algunos de sus proyectos, libros que dan lugar al trabajo manual de la escritura, con diversos pigmentos, sustratos y proporciones. El trabajo de Claudio Gil, explora la comunicación visual de forma directa, pues interviene tela, vidrio, piedra y otros muchos materiales para exponer su trabajo caligráfico, trabajando de forma exploratoria las dimensiones de un trabajo artesanal, todo hecho a pulso.
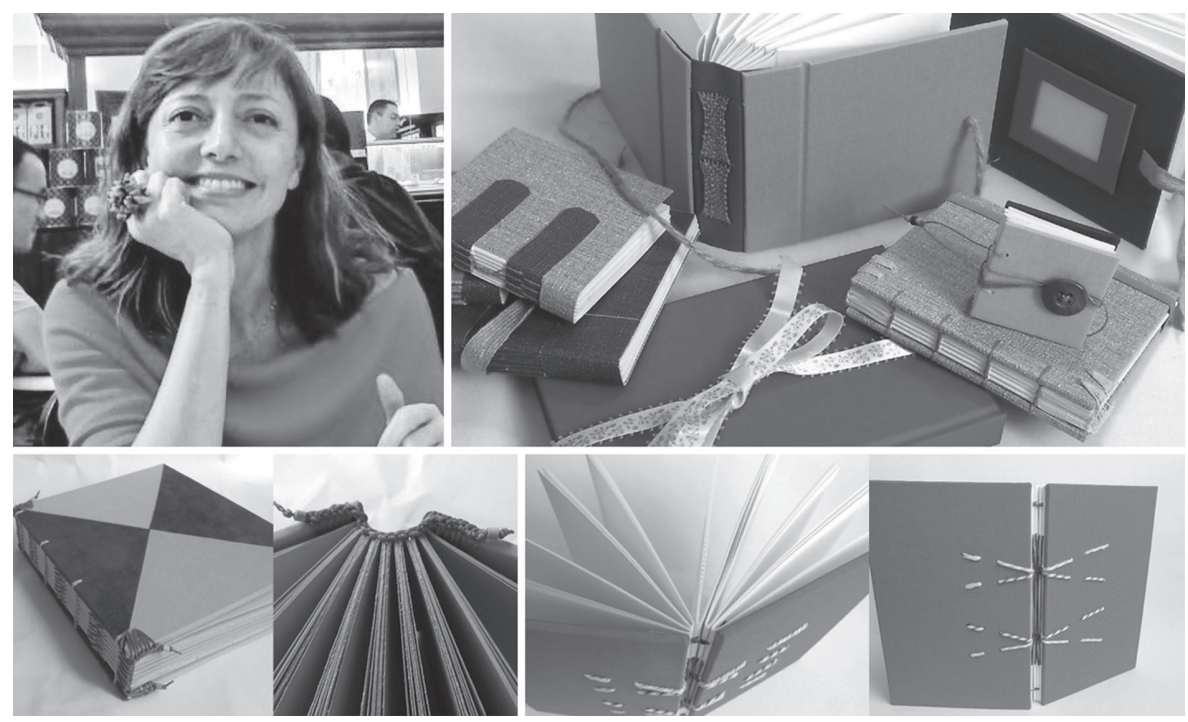

Imagen 8, 9,10 y 11. Fotos de Gabriela Irigoyen y algunos de sus libros en los que se puede ver el detalle de su trabajo artesanal. Fuente: https://gabrielairigoyen.myportfolio.com/ 


\section{Ideas finales}

Parte de las entrevistas a partir de las que discurre este artículo se realizaron con preguntas puntuales acerca del trabajo artesanal y el diseño. Para ambas diseñadoras entrevistadas el trabajo artesanal ha ido de la mano con el trabajo de diseño, fusionando los conocimientos sintéticos y los simbólicos, con una suerte de apropiación identitaria que conlleva la experiencia que tienen ambas en diversas áreas. Asimismo cuentan con el dominio de diversas técnicas y a la vez exploran en el diseño nuevas formas de comunicarse. Por un lado Parisa a partir de su trabajo de identidad y cartel, y por otro Gabriela con el diseño de libros. Ambas han aprovechado de la tecnología la facilidad de la comunicación y difusión de su trabajo, pero no por ello se han distanciado de ejercer sus conocimientos tácitos en propuestas únicas.

El conocimiento exhaustivo de su trabajo, permitió registrar el entusiasmo y la sorpresa con la que los jóvenes descubren en sus diseños el trabajo manual que está detrás. No todo es retoque o trabajo digital, las soluciones sustanciales de lo hecho a mano en el diseño siguen siendo atractivas y valoradas de distintas formas. Algunos preferirán siempre el diseño único, el que nadie más puede tener o del que solo hay contadas piezas porque no existe más el molde. Las soluciones artesanales evidentemente muestran el dominio de diversas técnicas, todas muy distintas pero que permiten dilucidar tangiblemente que aún en nuestra actualidad se puede hacer, difundir e incluso vender el diseño.

Si bien en un principio el trabajo artesanal atendía a necesidades sociales con objetos útiles y funcionales, también puede seguir conservándose como expresión viva del trabajo de expertos que mantiene el conocimiento de diversas técnicas, fortaleciéndose con autenticidad del sello personal que identifica a quien lo diseña y a la entidad que lo acoge. El diseñador puede apropiarse de las técnicas, pero será mucho más enriquecedor el hacer su transición compartiendo lo que sabe, aquello que ha aprendido a lo largo del tiempo como aprendiz y luego como maestro legándolo a otros, para que su conocimiento no se pierda. De este modo el diseño cómo disciplina siempre sigue vinculado a la delicada articulación entre el quehacer manual y el desarrollo creativo, sin limitarse nunca por el desarrollo tecnológico. Antes bien, potenciándose como herramienta para conservar evidencias en videos, grabaciones y tutoriales que puedan servir para el futuro.

\section{Notas}

1. Véase en http://sgeia.galeon.com/escuelas/artesanias.htm\#antecedentes

2. Recordemos la importante aportación del ilustre diseñador de moda Ramón Valdiosera y su Rosa mexicano, que en 1949 lograra mostrar en Nueva York el peculiar color en una colección de textiles tradicionales mexicanos. Véase en: http://revistapicnic.com/ ramon-valdiosera-rosa-mexicano/

3. Véase en: https://www.cultura.gob.mx/turismocultural/hilosyentramados/index.html\#hero

4. Consultado abril 2019 
5. Estas entrevistas se hicieron en su idioma original, con Parisa en inglés y con Gabriela en portugués, rescatando únicamente lo más importante para el artículo, ya que su respuesta pronta y favorable fue mucho más extensa. Se le agradece a ambas.

6. Un tipo de escritura en piedra de granito en tres idiomas, el viejo persa, Neo-babylonian y Neo-Elamilte, situadas muy cerca de Hamedan, República Islámica de Irán.

7. Screentone era una técnica para aplicar texturas y sombras a los dibujos, utilizada como alternativa a la eclosión, procesos de transferencia de hojas flexibles y adhesivas, impresas con textura y que se frotaban para su transferencia a diversos sustratos. En la actualidad se simula con gráficos y texturas en computadora. Las marcas Zip-A-Tone, Chart-Pak, y Letratone de Letraset, prácticamente ya no existen, más que en el recuerdo de aquellos que las usaron.

\section{Lista de referencias bibliográficas}

Asheim, B. (2007) Sistemas regionales de innovación y bases del conocimiento diferenciadas: un marco teórico analítico. En: Buesa, M. (Coord.), Sistemas regionales de innovación: nuevas formas de análisis y medición. Madrid: Funcas.

Augé, M. (2000) El diseño y el antropólogo, revista Experimenta n 32, Barcelona.

Bauman, Z. (2003) Modernidad Líquida, Buenos Aires, Fondo de Cultura Económica de Argentina S.A.

Baudrillard, J. (1969) El sistema de los objetos. Siglo XXI editores

Bordieu, P. (2007) Espacio social y poder simbólico en: Bourdieu, Pierre. Cosas Dichas, Barcelona: Editorial Gedisa

Castells, M. (1997) La era de la Información: economía sociedad y cultura. Alianza Madrid

Coriat, B. (1982) El taller y el Robot. Ensayos sobre fordismo y la producción en masa en la era de la electrónica. Siglo XXI editors

Coriat, B. (1992) Pensar al revés (trabajo y organización en la empresa japonesa), siglo XXI, México/España.

Damasio, A. (2002) El error de Descartes. Barcelona; Crítica.

De la Garza Toledo, Enrique (1988) coord. Estrategias de modernización empresarial en México. Flexibilidad y control sobre el proceso de trabajo. México: Fundación F. Ebert.

Cardale de Schrimpff, D. y Niño I. (2016) Aproximación al conocimiento de los colorantes en la comunidad indígena Ika de la Sierra Nevada de Santa Marta (departamento del Cesar, Colombia) https://journals.openedition.org/nuevomundo/69205?lang=es\#abstract

Droste, M. (2006) Bauhaus. 1919-1933. Reform und Avantgarde. Taschen

Gillmor, D. (2006). We the Media: Grassroots Journalism by the People, for the People. Sebastopol, CA: O'ReillyMedia

Esnaurrizar F. (21 de septiembre 2017) Alimentos orgánicos, tendencia e inversión. Disponible en: https://www.eleconomista.com.mx/finanzaspersonales/Alimentos-organicostendencia-e-inversion-20170922-0027.html

Horace L. y Faurote, F. (1915) Ford Methods and the Ford Shops. The Engineering magazine company. Nueva York,

Irigoyen, G, (diciembre 2, 2018) Comunicación personal. 
Irigoyen, G. (2019). Página personal. Recuperado de https://gabrielairigoyen.myportfolio. com

Lehm, Z. y S. Rivera (1988) Los artesanos libertarios y la ética del trabajo. La Paz: Ediciones del Taller de Historia Oral Andina (THOA)

Lundvall, B y Johnson, B (2016) The Learning economy and the economics of hope. Anthem press. London

Marinas, J. M. (1998). Tendencias y emergentes de la cultura del consumo. Documentación Social , 141-153.

Kloss G. (octubre 2006) Algunos apuntes históricos sobre las escuelas de diseño. Disponble en: https://encuadre.org/algunos-apuntes-historicos-sobre-las-escuelas-de-diseno/

Neffa, J. C. y E. de la Garza Toledo (2010) "Modelos económicos, modelos productivos y estrategia de ganancias: conceptos y problematización”. En Trabajo y modelos productivos en América Latina. Argentina, Brasil, México y Venezuela luego de la crisis del modelo neoliberal, Buenos Aires, Clacso.

Nonaka; I. (2007). "The Knowledge-Creating Company: How Japanese Companies Create the Dynamics of Innovation": "How Japanese Companies Create the Dynamics of Innovation. Oxford University Press.Recuperado de https://hbr.org/2007/07/the-knowledgecreating-company

Rotman, M. (2003). Modalidades productivas artesanales: expresiones de lo local en un mundo globalizado. Campos-Revista de Antropología, 3.

Sennett, R. (2009). El artesano. Editorial Anagrama. Barcelona.

Tashakori, P, (noviembre 28, 2018) comunicación personal.

Tashakori, P. (2019). Página personal. Recuperado de http://www.parisatashakori.com

Womack Jr., John. (2007) Posición estratégica y fuerza obrera. Hacia una nueva historia de los movimientos obreros. México: Fondo de Cultura Económica.

https://hbr.org/2007/07/the-knowledge-creating-company, consultado enero 2019

https://www.cultura.gob.mx/turismocultural/hilosyentramados/index.html\#hero

consultado abril 2019

Abstract: Since its inception the work of graphic design had the intention of reproducing and multiplying, being the editorial work and its various publications which under the principles of dissemination, generated increasingly higher editions, both in number and quality. However, in a context of postmodernity, where the contents, symbolic and material to name a few, have changed, it is argued that currently and perhaps in a return to the origin, there is a tendency to make unique design products, for artisanal that some also present as sustainable, with use and reuse of various materials seeking less waste, some innovation and that clearly become unique and irreplaceable, where the post-Fordist economy happens to mass production and has a different assimilation of objects cultural and symbolic despite technological advances. This text analyzes from different perspectives and interviews, the work of designers who bet on handicraft work as an intervention for projects such as posters, books and other design objects, allowing us to approach contemporary design, in an attempt to assimilate their assessment against an almost immaterial world. 
Keywords: artisan work - contemporary design - identity - production - valuation

Resumo: Desde o seu início, o design gráfico teve a intenção de se reproduzir e multiplicar-se, sendo o trabalho editorial e suas diversas publicações, que, sob os princípios de difusão, geraram edições cada vez mais altas, tanto em número como em qualidade. No entanto, e em um contexto de pós-modernidade, onde os conteúdos, simbólicos e materiais, para citar alguns, foram mudando, se sustenta que, atualmente, talvez uma volta às origens, surge uma tendência para realizar produtos de design únicos, artesanais, que alguns também se apresentam como sustentáveis, na utilização e reutilização de diversos materiais, procurando menos lixo, uma certa inovação, e que, evidentemente, tornam-se singulares e insubstituíveis, apesar dos avanços tecnológicos, numa economia após-fordista onde acontece a produção em massa e tem uma assimilação diferente de objetos culturais e simbólicos.

Este texto analisa a partir de várias visões e entrevistas, o trabalho de designers que apostam no trabalho artesanal como uma intervenção para projetos como o cartaz, livros e outros objetos de design, permitindo-nos uma aproximação com o design contemporâneo na tentativa de assimilar a sua classificação frente a um mundo quase imaterial.

Palavras chave: trabalho artesanal - design contemporâneo - identidade - produção - valorização

[Las traducciones de los abstracts fueron supervisadas por el autor de cada artículo] 